\title{
Analysis of Flow Angles and Flow Velocities in Spool Valves for the Calculation of Steady-State Flow Forces
}

\author{
Patrik Bordovsky, Hubertus Murrenhoff \\ Institute for Fluid Power Drives and Controls (IFAS), RWTH Aachen University, Aachen, Germany \\ E-mail: Patrik.Bordovsky@ifas.rwth-aachen.de, Hubertus.Murrenhoff@ifas.rwth-aachen.de
}

\begin{abstract}
A detailed analysis of the flow inside valves has become necessary for the optimisation of their static and dynamic performance. For this purpose, the contours of metering edges as well as the shapes of sleeves, respectively of valve blocks, can be modified, resulting in different flow patterns. In addition, the flow velocities and flow angles on defined areas inside valves are needed for the estimation of physical quantities such as flow rates, flow forces, etc.
\end{abstract}

Within this paper, measurements and CFD-simulations of a 2/2-way spool type test valve are analysed regarding flow angles and flow velocities including their distribution on the inlet and outlet areas. Different spool edge geometries are investigated in both flow directions. Furthermore, the impact of a chamfer and a fillet on a spool edge, on the flow angles and the flow velocities are analysed.

The analysis results show that the shape of a spool edge influences the flow angles and the flow velocities. Both flow variables are significantly affected by the direction of the fluid flow through the valve. Moreover, considering the same inlet area, an increasing chamfer width, respectively an increasing fillet radius, result both in lower inlet and outlet flow angles.

Keywords: Flow Angle, Flow Velocity, Steady-State Flow Force, Spool Valve

\section{Introduction}

The first research on jet angles was conducted by von Mises [1] in 1917. He experimentally determined the flow coefficients and jet angles of water flowing out of a circular tank with sharp-edged outlets into the surrounding air, as depicted in fig. 1.

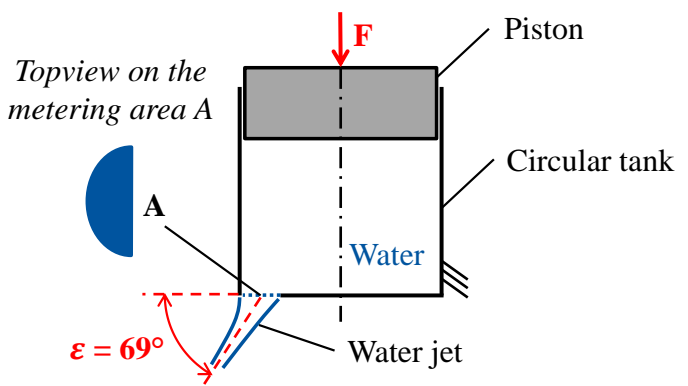

Figure 1: Experimental setup by von Mises

Based on his experiments, he found that the jet angle approaches the value $69^{\circ}$. As it can be seen in fig. 1 , he considered the angle between the centre line of a free jet and the horizontal line. In other words, von Mises did not focus on the average jet angle evaluated on the metering area A. Consequently, before using the $69^{\circ}$-jet-angle value, it is necessary to review von Mises' assumptions and statements. $\mathrm{He}$ assumed a steady-state, inviscid, eddy-free, nonrotational and two-dimensional fluid flow. Moreover, the tank was pressurised by a piston, so the fluid motion was caused by the pressure difference and not only by the gravitational force. Nevertheless, von Mises mentioned that slight outlet edge modifications, e.g., a fillet or a chamfer, result in different jet angles. In valves, there are several unique shapes of metering edges, which are manufactured to fulfil desired valve performance. Consequently, von Mises' results should not be seen as generally valid since his assumptions are often not fulfilled in spool valves.

Backé [2] set up an approximation function for the inlet jet angle expressed by eq. (1)

$$
\cos \varepsilon=0,358+\frac{0,577}{1+0,642\left(\frac{x_{1}}{\Delta r}\right)^{1,26}}
$$

where $x_{1}$ is the spool position and $\Delta r$ is the height of the radial clearance between the spool and the sleeve.

Compared to the inlet jet angles, little research was conducted on the outlet jet angles. Usually, the outlet angle is considered to be $90^{\circ}$ for the calculation of the steady-state flow-force (hereinafter referred to as flow force) [3]. However, Ye [4] claims that the outlet angle deviates from that value and Schrank [5], Tanaka [6], Lugowski [7], and 
Yuan [8] suggested that the outlet angles should be considered for the calculation of flow forces since the outlet angles are greater than $90^{\circ}$.

Modifications of metering edges are commonly used for the compensation of flow forces. For instance, Okungbowa [9] achieved the flow force reduction by a rim-shaped geometry. Furthermore, Kipping [10] stated that the outflow from the spool chamber is highly turbulent and threedimensional. Bordovsky [11] added that the evaluation of the outlet velocities can be inaccurate. All in all, before calculating the flow force, the flow patterns in the investigated valve should be analysed to prove the assumptions.

Several experimental studies were conducted to investigate flow patterns in valves by using dynamic similarity, e.g., by Kipping [10]. Usually, a scaled valve model was used with water instead of hydraulic oil, which results in lowering the pressure differentials, and hence the flow velocities as well. The dynamic similarity should not be seen as absolutely valid, though. Flow patterns can be also visualised by using the Particle Image Velocimetry (PIV) method. For instance, Del Vescovo [12] utilised PIV for an analysis of velocity profiles. However, he was not able to estimate the outlet angles due to issues with the camera focus.

Nowadays, flow patterns inside valves are usually investigated by CFD simulations. For instance, Ye [4] used CFD simulations to describe effects of the metering edge shape on the flow characteristics. Borghi [13] also determined jet angles of differently shaped metering edges by using CFD simulations. Besides measurements, the simulative approach was utilised in this study as well.

\section{Theory}

The law of the linear momentum conservation is often used to analyse the flow forces acting on a fixed control volume as shown in fig. 2 .

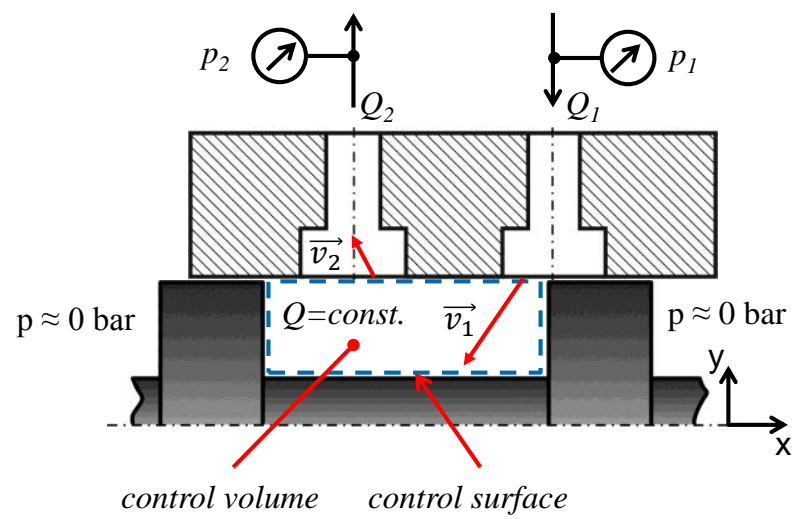

Figure 2: Sketch of a simplified valve

Among various disturbance forces, the flow forces are considered to be most relevant in spool valves. They usually act in the closing direction. The flow forces arise due to the change of momentum over time within the control volume. A detailed derivation of the flow forces can be found in the literature $[3,5,14]$. In order to approximate the flow forces, following assumptions are made: two-dimensional incompressible viscous flow, square-edged spool, no radial clearance between the spool and the sleeve, a nondeformable non-accelerating ideal annular control volume, enclosed by the control surface, only axial forces acting on the control surface. Consequently, the flow force can be calculated according to eq. (2) for the control volume defined in fig. 2, where $\rho$ is the fluid density, $Q$ the flow rate and $\overline{v_{1, x}}, \overline{v_{2, x}}$ are the average axial velocities on the inlet $\left(A_{1}\right)$, respectively the outlet $\left(A_{2}\right)$ area.

$$
\sum F_{x}=\frac{d \vec{I}}{d t}=-F_{F l}=\rho \cdot Q \cdot\left(\overline{v_{1, x}}-\overline{v_{2, x}}\right)
$$

As can be seen in eq. (2), the flow force equals the negative value of the net axial force acting on the control volume. For the calculation, it is necessary to evaluate the axial flow velocities on the inlet and the outlet areas as shown in fig. 3 .

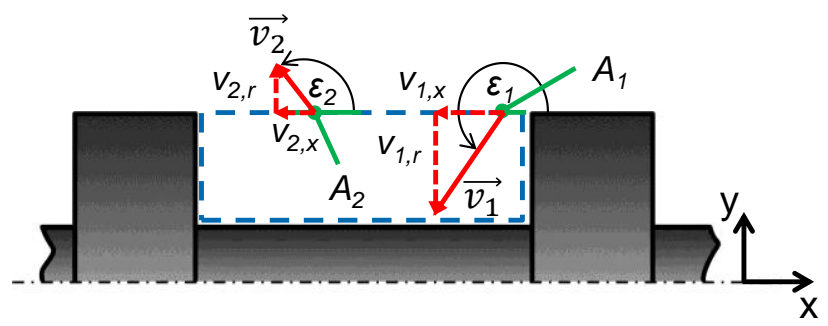

Figure 3: Flow velocities on the metering areas in case of the inlet throttling

In relation to fig. 3 , the average axial flow velocities can be obtained from eq. (3)

$$
\overline{v_{l, x}}=\left|\overrightarrow{v_{l}}\right| \cos \overline{\varepsilon_{l}}
$$

and the average radial flow velocities can be calculated according to eq. (4). The y-component of the flow velocity corresponds to the radial one.

$$
\overline{v_{l, r}}=\left|\overrightarrow{v_{l}}\right| \sin \overline{\varepsilon_{l}}
$$

In reality, there are additional pressure losses when the fluid flows through valves. These losses are expressed by the discharge coefficient $\alpha_{D}$. Hence, the real flow velocities are lower than the theoretical ones. The average real radial inlet velocity $\overline{v_{1, r}}$ can be approximated by eq. (5)

$$
\overline{v_{1, r}}=-\alpha_{D} \sqrt{\frac{2 \Delta p}{\rho}}
$$

respectively by eq. (6) for the average real radial outlet velocity $\overline{v_{2, r}}$, which can be derived from the continuity equation of the flow rate.

$$
\overline{v_{2, r}}=-\frac{A_{1}}{A_{2}} \overline{v_{1, r}}=\frac{A_{1}}{A_{2}} \alpha_{D} \sqrt{\frac{2 \Delta p}{\rho}}
$$

The average axial flow velocities are calculated from the radial velocities and corresponding flow angles. So the flow rate can generally be calculated from the orifice equation (eq. 7) 


$$
Q=\alpha_{D} A_{1} \sqrt{\frac{2 \Delta p}{\rho}}
$$

where $\Delta p$ is the pressure drop between the pressuremeasurement ports 1 and 2 (see fig. 2). The area $A_{1}$ describes the real metering area, not the narrowest metering area, often referred to as vena contracta [14] since the location and the area of the vena contracta are unknown.

By combining eq. (4) with eq. (5), the absolute value of the average inlet velocity can be obtained from eq. (8).

$$
\left|\overrightarrow{v_{1}}\right|=-\alpha_{D} \sqrt{\frac{2 \Delta p}{\rho}} \frac{1}{\sin \overline{\varepsilon_{1}}}
$$

By inserting eq. (8) into eq. (3), the approximated average inlet axial velocity is described by eq. (9).

$$
\overline{v_{1, x}}=-\alpha_{D} \sqrt{\frac{2 \Delta p}{\rho}} \frac{\cos \overline{\varepsilon_{1}}}{\sin \overline{\varepsilon_{1}}}=-\alpha_{D} \sqrt{\frac{2 \Delta p}{\rho}} \cot \overline{\varepsilon_{1}}
$$

Similarly, the average outlet axial velocity can be approximated by eq. (10).

$$
\overline{v_{2, x}}=\overline{v_{2, r}} \cot \overline{\varepsilon_{2}}=\frac{A_{1}}{A_{2}} \alpha_{D} \sqrt{\frac{2 \Delta p}{\rho}} \cot \overline{\varepsilon_{2}}
$$

As can be seen from eq. 9 and eq. 10, it is necessary to know the average inlet and outlet angles on the corresponding metering areas, which are part of the control surface. Due to the difficulty of flow-angle measurement, the flow angles are evaluated from CFD simulations.

For the reverse flow, i.e., outlet throttling, the flow quantities are denoted according to fig. 4, and distinguished by an apostrophe from the flow quantities of the inlet throttling. The area $A_{2}{ }^{\prime}$ denotes the chamber inlet and the area $A_{1}{ }^{\prime}$ the chamber outlet. If any of the flow angles is greater than $180^{\circ}$, the value of $180^{\circ}$ can be subtracted from it for the purpose of the flow-force calculation due to the cotangent function.

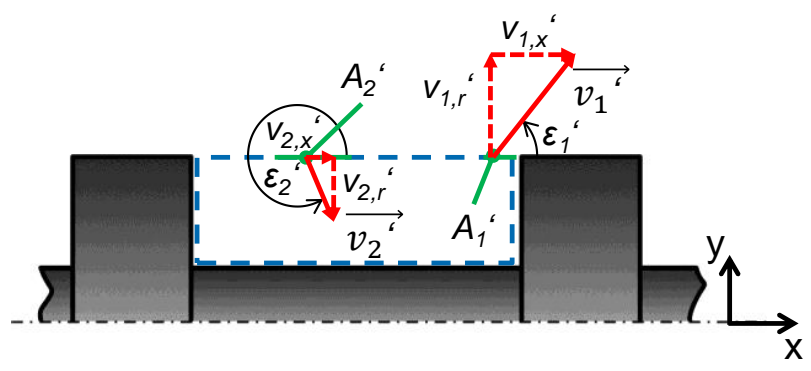

Figure 4: Flow velocities on the metering areas in case of the outlet throttling

The flow force for the outlet throttling has the same direction as for the inlet throttling and can be approximated by eq. 11 .

$$
\sum F_{x}{ }^{\prime}=-F_{F l}{ }^{\prime}=\rho \cdot Q \cdot\left({\overline{v_{2, x}}}^{\prime}-{\overline{v_{1, x}}}^{\prime}\right)
$$

\section{Experiment}

The average radial flow velocities were evaluated from measurements of a $2 / 2$-way proportional spool-type valve, which is shown in fig. 5. The valve consists of a valve block, a sleeve, two lids, and a spool, which can be replaced easily. It has two pressure ports $\mathrm{P}$ and $\mathrm{T}$ and two leakage ports $\mathrm{L}$, which are drained to a pressureless external tank. All components were made of steel.

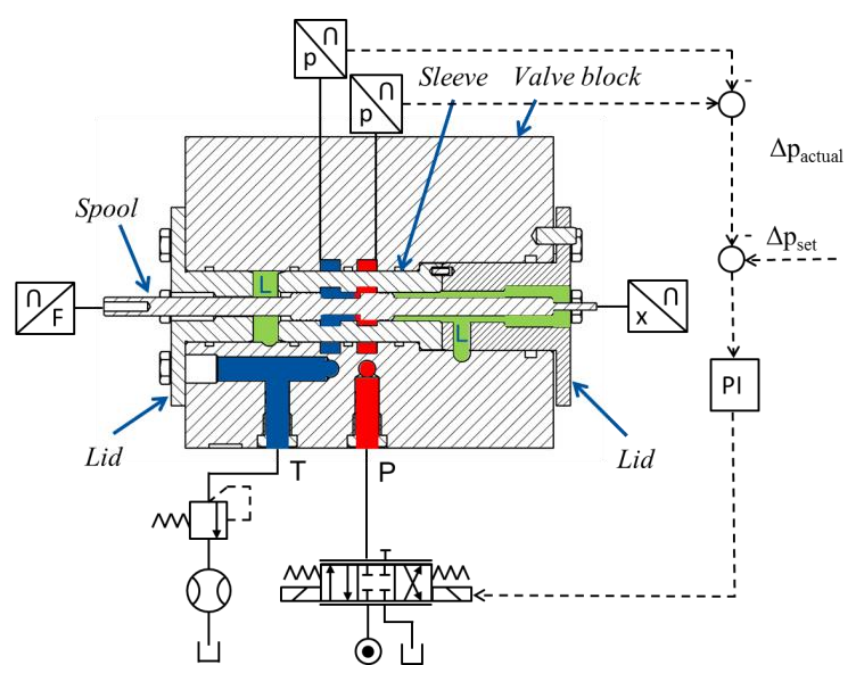

Figure 5: Test valve including a simplified hydraulic circuit diagram

A position sensor was placed on the right-hand side of the spool. A weakly preloaded spring mounted on the position sensor ensured the contact between the spool and this sensor. A load cell was placed on the left-hand side of the spool. The pressure differentials $(10,15,20,30,40,50$ and 70 bar) between the ports $\mathrm{P}$ and $\mathrm{T}$ were controlled by a servovalve and a PI controller. The tank port (T) was preloaded using a pressure relief valve to the pressure of 100 bar to prevent cavitation. The flow rate was measured behind the pressure relief valve at discrete spool positions. The measurements were carried out with the oil HLP46 at an approximately constant oil temperature of $60^{\circ} \mathrm{C}$.

Two square-edge spools, one with the chamber length $L$ of $13 \mathrm{~mm}$ (SE13) and another one with the chamber length $L$ of $20 \mathrm{~mm}$ (SE20), and a bevel-edged spool (BE) were used for flow-velocity measurements as depicted in fig. 6 .

The average flow velocities of all spools were evaluated on the same inlet and outlet areas from the measured flow rate. Hence, the narrowest inlet area was not considered in case of the spool BE within this paper.

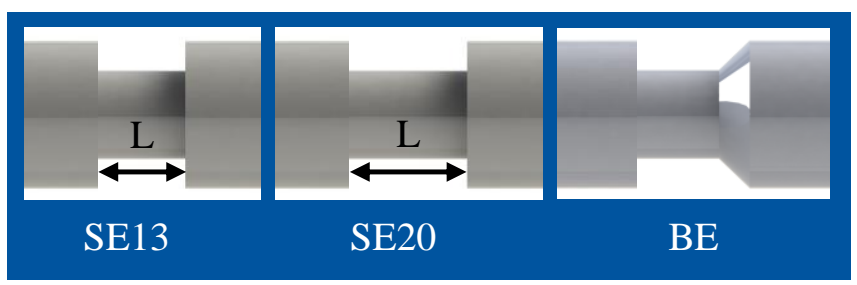

Figure 6: Spools used for measurements 
The test valve is integrated into a test rig. The valve was supplied via a connection block, and the spool was moved by an electric cylinder (see fig. 7). In order to change the flow direction, an additional block was mounted between the valve and the connection block, inverting the flow direction from port $\mathrm{T}$ across the valve to port $\mathrm{P}$.

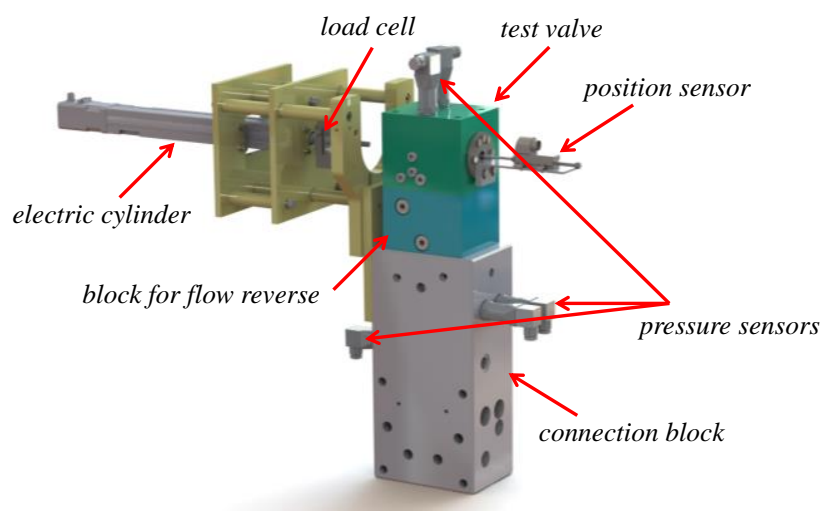

Figure 7: Test rig used for measurements

\section{CFD simulation}

Three-dimensional, steady, incompressible, isothermal and viscous CFD simulations were carried out in ANSYS CFX 17.0. Despite two symmetrical planes of the valve, the whole fluid domain was modelled, which resulted in better accuracy when comparing the simulation results with the measurements. The fluid domain has two inlets and two outlets. A mass flow rate on the inlets and a static pressure of $100 \mathrm{bar}$ on the outlets were defined as boundary conditions. The radial clearance between the spool and the sleeve was neglected. The outlet throttling was simulated with the same boundary conditions as the inlet throttling. The mesh was generated from tetrahedrons and prism layers as it can be seen in fig. 8. The sleeve edge opposite to the spool edge was modelled with a chamfer of $0.075 \mathrm{~mm} \mathrm{x} 45^{\circ}$.

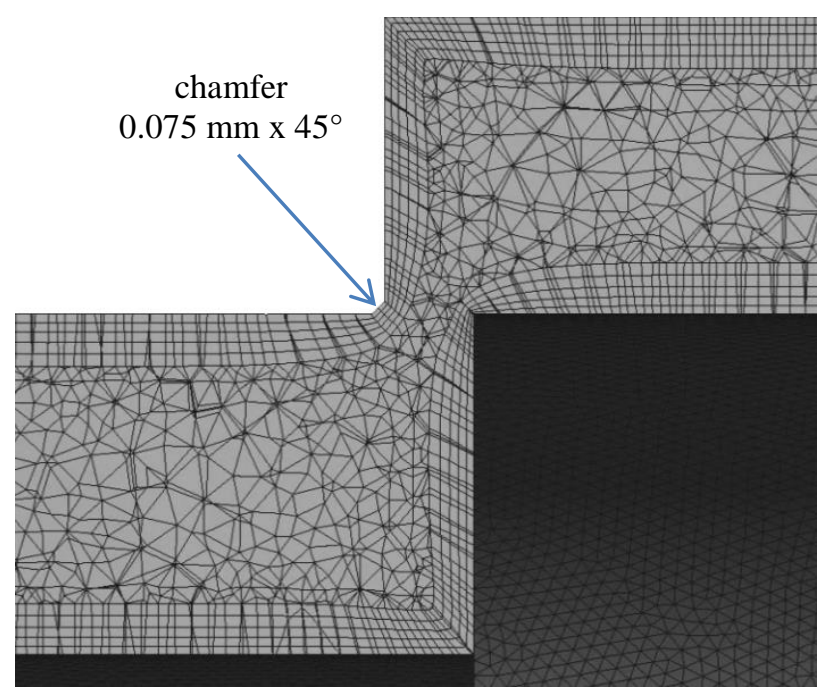

Figure 8: Detail of the mesh around the metering edge (spool SE at $x=0.6 \mathrm{~mm}$ )

Besides the measured spools, a fillet-edged (FE) and a chamfer-edged (CE) spool were investigated in both flow directions with different fillet radii and chamfer widths ranging from 20 to $200 \mu \mathrm{m}$. A constant chamfer angle of $45^{\circ}$ was set. Additional CFD simulations were carried out with the chamfer dimensions $0.3 \times 60^{\circ}$. Figure 9 shows spools, which were simulated in addition to the spool SE13, SE20 and BE. The flow reversal in CFD simulations was done by changing inlets to outlets and vice versa.

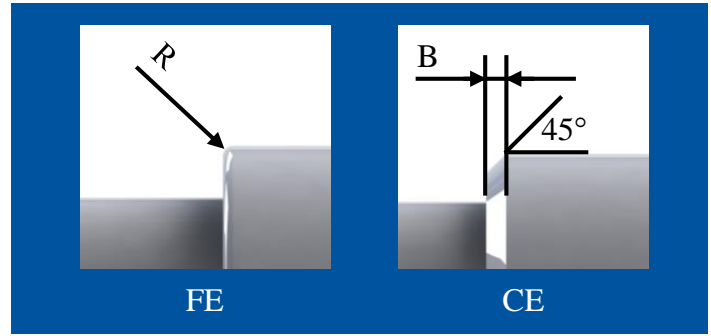

Figure 9: Geometries of additionally simulated spools

Both the average radial and the axial flow velocities were evaluated on the inlet and the outlet areas using the areaweighted average expressed by eq. 12 .

$$
\overline{v_{l, C F D}}=\frac{1}{A_{i}} \int v_{i} d A
$$

The average flow angles were calculated from the axial and radial flow velocities according to eq. 13 .

$$
\overline{\varepsilon_{l}}=\operatorname{arccot} \frac{\overline{v_{l, x, C F D}}}{\overline{v_{l, r, C F D}}}
$$

\section{Results}

The average radial flow velocities were evaluated from the measurements for both flow directions. The radial flow velocities $v_{1, r}$ and $v_{1, r}{ }^{\prime}$ are shown for the spool $\mathrm{SE}$ at the spool positions of $0.2,0.6$ and $0.9 \mathrm{~mm}$ in fig. 10 . The outlet radial flow velocities $v_{2, r}$ and $v_{2, r}{ }^{\prime}$ are shown in fig. 11 .

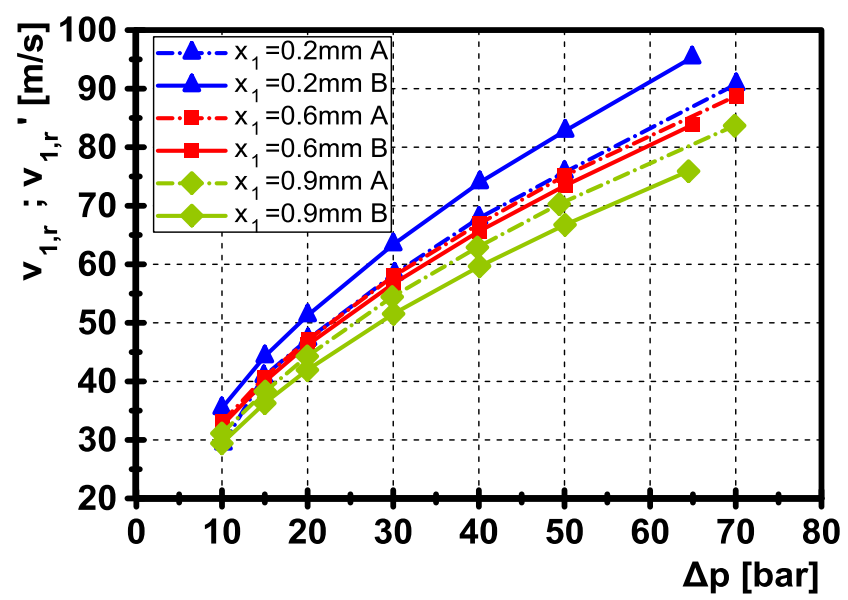

Figure 10: Measured average radial velocities $v_{1, r}$ and $v_{1, r}$, of the spool SE20 in both flow directions (A: inlet throttling, B: outlet throttling) 


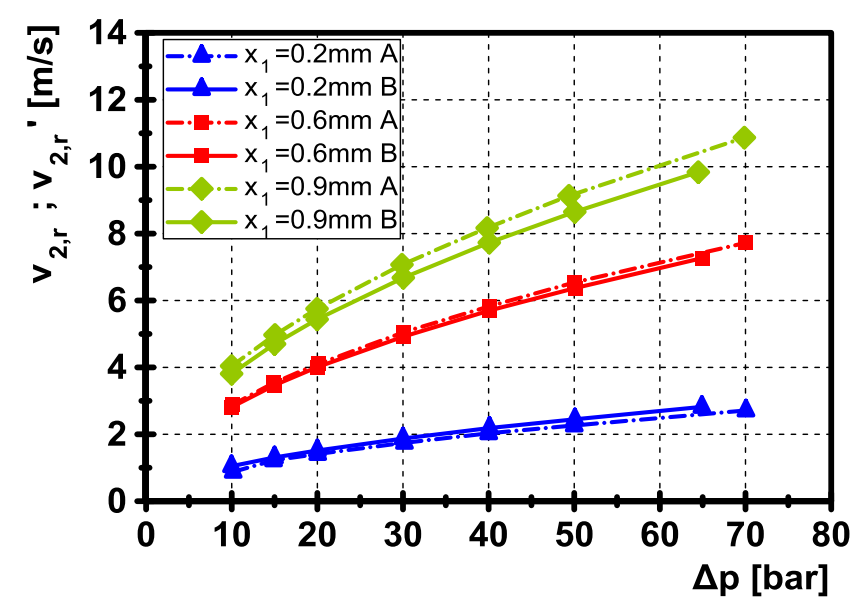

Figure 11: Measured average radial velocities $v_{2, r}$ and $v_{2, r}$, of the spool SE20 in both flow directions

(A: inlet throttling, B: outlet throttling)

Figure 12 and fig. 13 show the measured radial flow velocities of different spools on the inlet, and on the outlet for the inlet throttling.

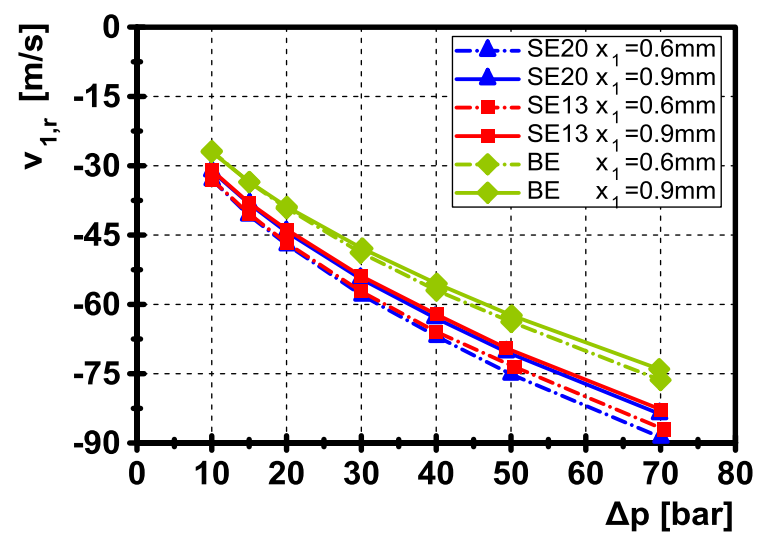

Figure 12: Comparison of the measured radial flow velocities $v_{1, r}$ for the inlet throttling of different spools

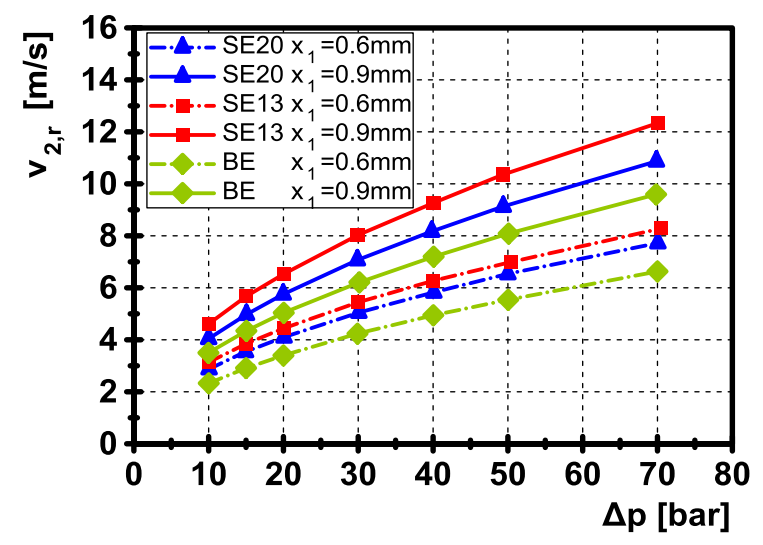

Figure 13: Comparison of the measured radial flow velocities $v_{2, r}$ for the inlet throttling of different spools

The measured and the simulated average radial flow velocities on the chamber inlet in case of the inlet throttling are compared for the spool SE in tab. 1, which also includes the relative error.

Table 1: Flow angles and flow velocities simulated for different chamfer widths in case of the inlet throttling

\begin{tabular}{|c|c|c|c|c|c|c|}
\hline$\Delta p$ & $\mathbf{v}_{1, \mathrm{r}, \mathrm{M}}$ & $v_{2, r, M}$ & $v_{1, r, C F D}$ & $v_{2, r, C F D}$ & $E_{R}: v_{1, r}$ & $E_{R}: v_{2, r}$ \\
\hline [bar] & {$\left[\mathrm{m} \cdot \mathrm{s}^{-1}\right]$} & {$\left[\mathrm{m} \cdot \mathrm{s}^{-1}\right]$} & {$\left[\mathrm{m} . \mathrm{s}^{-1}\right]$} & {$\left[\mathrm{m} . \mathrm{s}^{-1}\right]$} & [\%] & [\%] \\
\hline 10 & $-34,0$ & 2,9 & $-32,4$ & 2,8 & $-4,6$ & $-4,4$ \\
\hline 20 & $-48,0$ & 4,1 & $-45,9$ & 4,0 & $-4,5$ & $-3,4$ \\
\hline 30 & $-58,8$ & 5,0 & $-56,3$ & 4,9 & $-4,4$ & $-2,5$ \\
\hline 50 & $-75,9$ & 6,5 & $-72,6$ & 6,4 & $-4,3$ & $-1,0$ \\
\hline 70 & $-89,7$ & 7,7 & $-85,9$ & 7,6 & $-4,2$ & $-1,0$ \\
\hline
\end{tabular}

Velocity vectors of the spool SE20 were observed for the spool position of $0.6 \mathrm{~mm}$ and the pressure differential of 50 bar. Figure 14 shows velocity vectors on the chamber inlet, and fig. 15 and fig. 16 show velocity vectors on two different positions on the chamber outlet: one directly under the outflow circular conduit, and the other one exactly between two outflow conduits. The vectors are plotted on lines, which are parallel to the $\mathrm{x}$-axis. Those lines are invisible, and the black lines illustrate the solid-body edges.

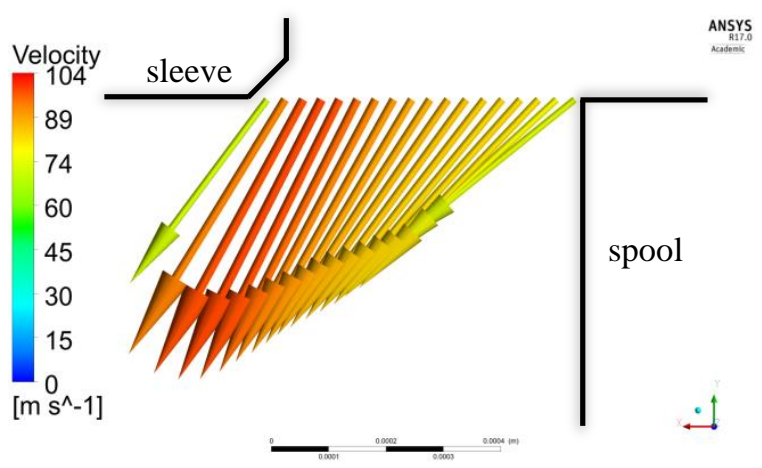

Figure 14: Spool SE20; $x_{1}=0.6 \mathrm{~mm} ; \Delta p=50 \mathrm{bar}$ Velocity vectors on the area $A_{1}$ in case of the inlet throttling

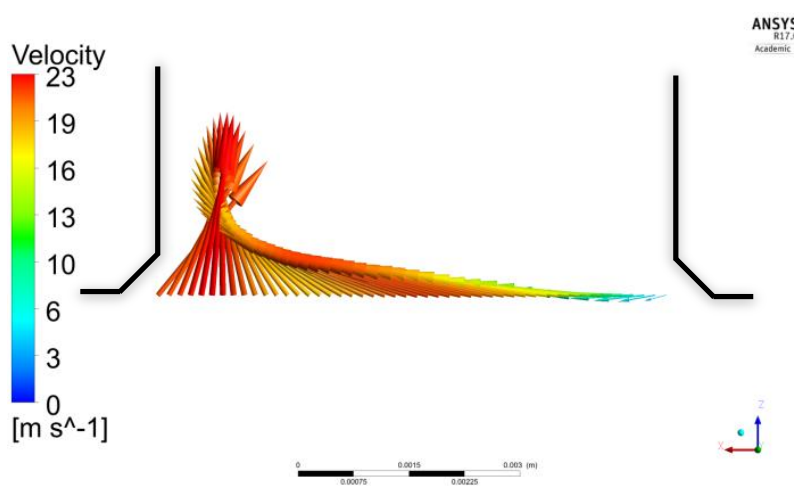

Figure 15: Spool SE20; $x_{1}=0.6 \mathrm{~mm} ; \Delta p=50 \mathrm{bar}$ Velocity vectors on the area $A_{2}$ under the circular conduit in case of the inlet throttling 


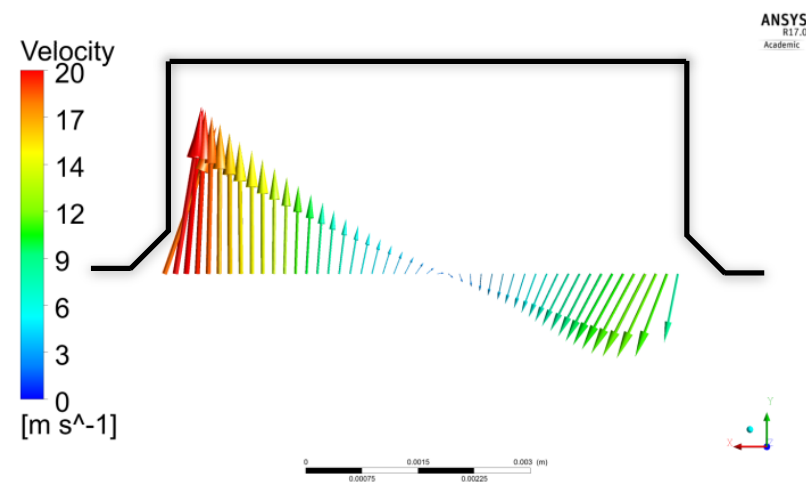

Figure 16: Spool SE20; $x_{1}=0.6 \mathrm{~mm} ; \Delta p=50 \mathrm{bar}$ Velocity vectors on the area $A_{2}$ between two circular conduits in case of the inlet throttling

Figure 17 shows profiles of radial flow velocity on the chamber inlet for the spool SE. These profiles were plotted for the spool position of $0.6 \mathrm{~mm}$ and the pressure differential of 10, 30, and 70 bar. Figure 18 and fig. 19 show profiles of radial flow velocity on the chamber outlet at two different positions: one directly under the outflow circular conduit, and the other one exactly between two outflow conduits. The quantity $\mathrm{x}$ is the $\mathrm{x}$-coordinate related to the spool edge on the inlet, respectively to the groove edge closer to the origin of the coordinate frame on the outlet.

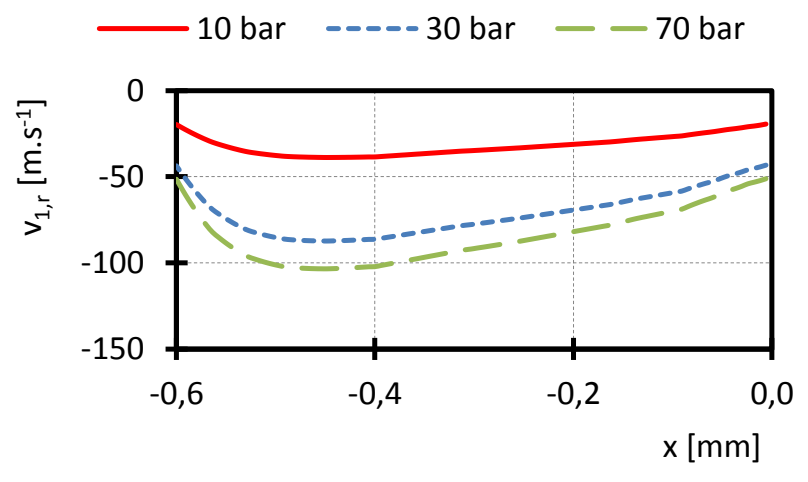

Figure 17: Spool SE20; $x_{1}=0.6 \mathrm{~mm}$; Profiles of radial velocities $v_{1, r}$ in case of the inlet throttling

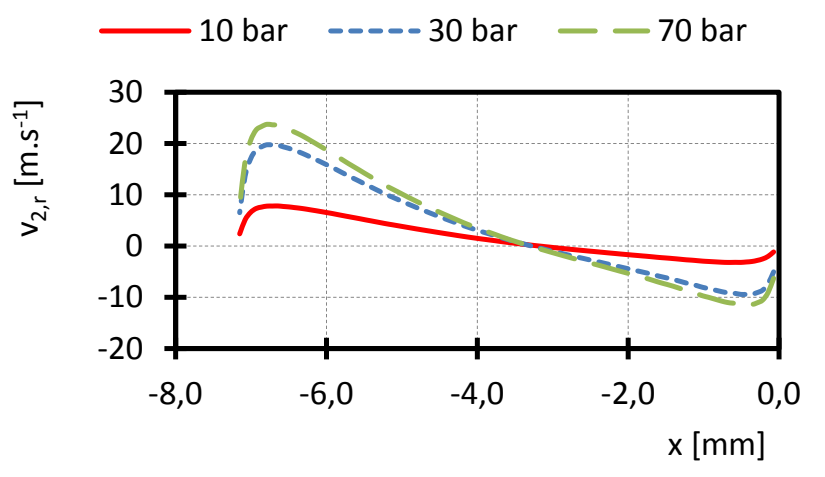

Figure 18: Spool SE20; $x_{1}=0.6 \mathrm{~mm}$; Profiles of radial velocities $v_{2, r}$ under the circular conduit in case of the inlet throttling

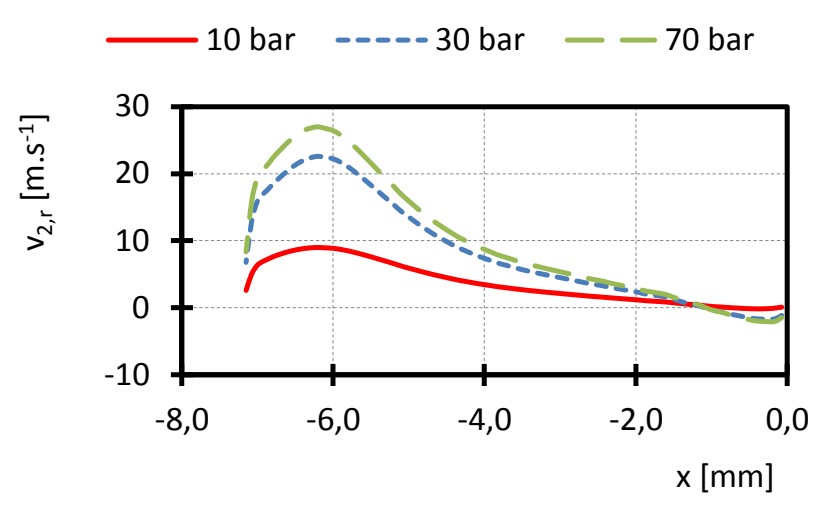

Figure 19: Spool SE20; $x_{1}=0.6 \mathrm{~mm}$; Profiles of radial velocities $v_{2, r}$ between two circular conduits in case of the inlet throttling

The average angles $\varepsilon_{1}$ and $\varepsilon_{1}$ ' of the spool SE are compared for both flow directions in fig. 20. The outlet angles $\varepsilon_{2}$ and $\varepsilon_{2}$ ' are depicted in fig. 21 .

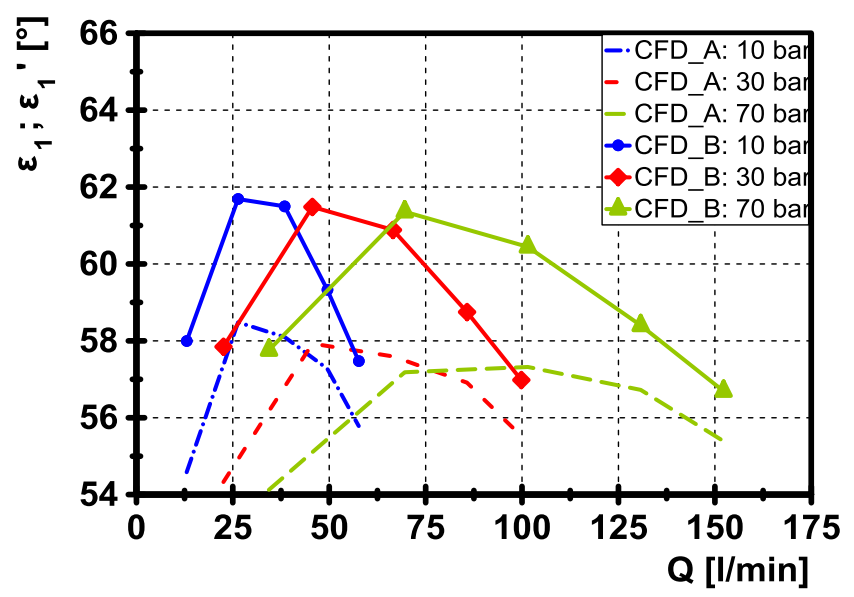

Figure 20: Comparison of the average flow angles $\varepsilon_{1}$ and $\varepsilon_{1}$ ' for the spool SE20 in both flow directions (A: inlet throttling, B: outlet throttling)

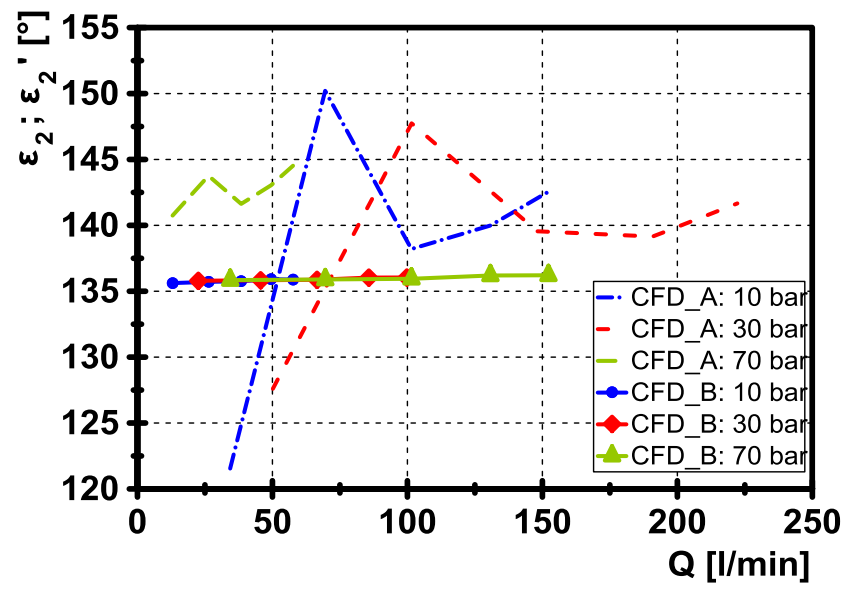

Figure 21: Comparison of the average flow angles $\varepsilon_{2}$ and $\varepsilon_{2}$ ' for the spool SE20 in both flow directions

(A: inlet throttling, B: outlet throttling)

The flow angles $\varepsilon_{1}$ ' of all spools are compared for the outlet throttling in fig. 22. The flow angles $\varepsilon_{2}$ ' are shown in fig. 23 . 
In both cases, the fillet radius of the spool FE is $0.02 \mathrm{~mm}$, and the chamfer dimensions of the spool CE are $0.02 \mathrm{~mm} \mathrm{x}$ $45^{\circ}$.

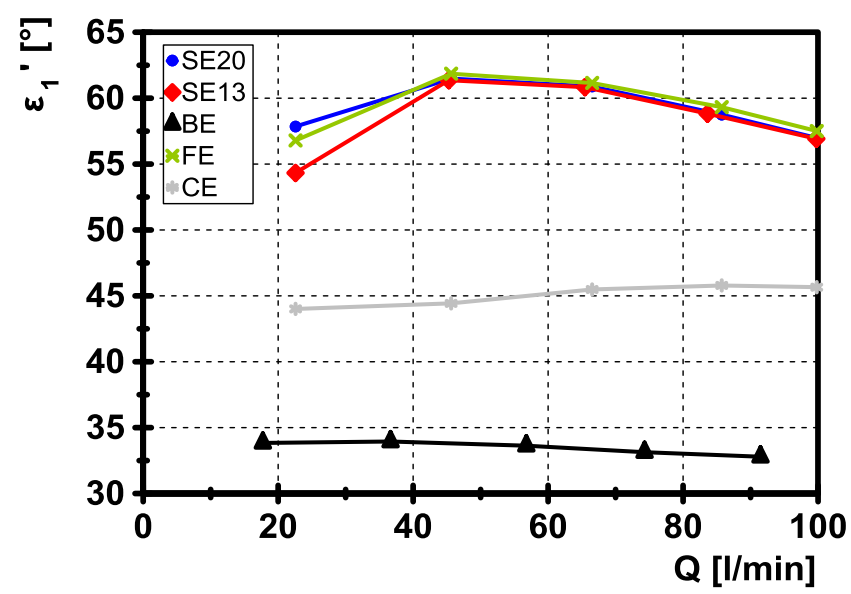

Figure 22: Comparison of the average flow angles $\varepsilon_{1}$ ' of all simulated spools for the outlet throttling

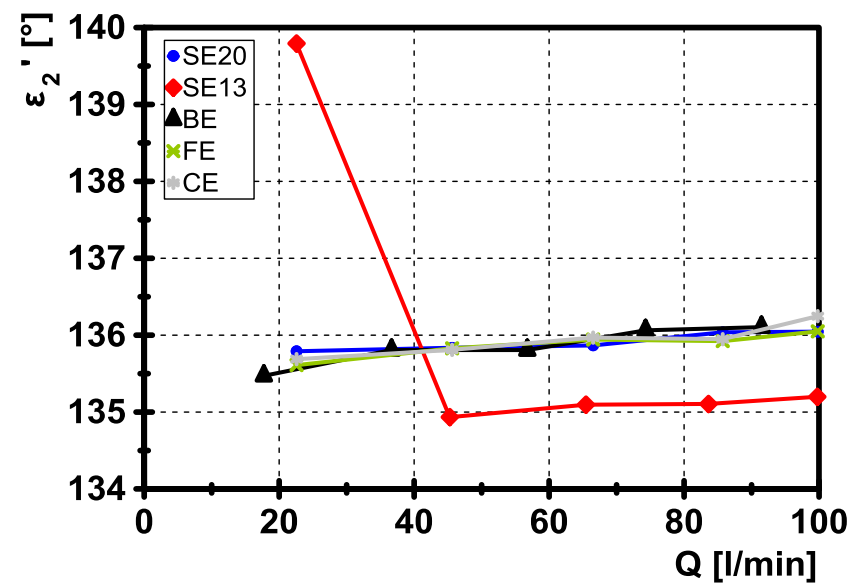

Figure 23: Comparison of the average flow angles $\varepsilon_{2}$ ' of all simulated spools for the outlet throttling

Table 2 and 3 list simulated flow angles and flow velocities of the spool $\mathrm{FE}$ with fillet radii $\mathrm{R}$ ranging from 20 to $200 \mu \mathrm{m}$ for the spool position of $0.6 \mathrm{~mm}$, the pressure differential of 50 bar for the inlet throttling, respectively the outlet throttling. Thus, a constant mass flow rate of $1.225 \mathrm{~kg} . \mathrm{s}^{-1}$ was set in all simulations. The spool stroke was lowered by the magnitude of the radius so the inlet area remained constant in all simulations.

Table 2: Flow angles and flow velocities simulated for different fillet radii in case of the inlet throttling

\begin{tabular}{|c|c|c|c|c|c|c|c|}
\hline $\mathbf{R}$ & $\varepsilon_{1}$ & $\varepsilon_{2}$ & $\mathbf{v}_{1, \mathrm{x}}$ & $v_{2, x}$ & $v_{1, r}$ & $v_{2, r}$ & $F_{F I}$ \\
\hline$[\mu \mathrm{m}]$ & {$\left[{ }^{\circ}\right]$} & {$\left[{ }^{\circ}\right]$} & {$\left[\mathrm{m} . \mathrm{s}^{-1}\right]$} & {$\left[\mathrm{m} . \mathrm{s}^{-1}\right]$} & {$\left[\mathrm{m} \cdot \mathrm{s}^{-1}\right]$} & {$\left[\mathrm{m} \cdot \mathrm{s}^{-1}\right]$} & {$[\mathrm{N}]$} \\
\hline 20 & 56,5 & 136,6 & $-50,6$ & $-6,6$ & $-76,3$ & 6,3 & $-50,6$ \\
\hline 50 & 57,2 & 138,1 & $-49,2$ & $-6,8$ & $-76,3$ & 6,1 & $-48,3$ \\
\hline 100 & 56,5 & 137,4 & $-50,6$ & $-6,7$ & $-76,4$ & 6,2 & $-48,8$ \\
\hline 150 & 54,7 & 136,8 & $-53,9$ & $-6,5$ & $-76,3$ & 6,1 & $-51,9$ \\
\hline 200 & 53,0 & 135,3 & $-57,5$ & $-6,2$ & $-76,2$ & 6,2 & $-56,0$ \\
\hline
\end{tabular}

Table 3: Flow angles and flow velocities simulated for different fillet radii in case of the outlet throttling

\begin{tabular}{|c|c|c|c|c|c|c|c|}
\hline $\mathbf{R}$ & $\varepsilon_{1}^{\prime}$ & $\varepsilon_{2}^{\prime}$ & $v_{1, x^{\prime}}$ & $v_{2, x^{\prime}}$ & $\mathbf{v}_{1, r^{\prime}}$ & $v_{2, r^{\prime}}$ & $F_{F I}$ \\
\hline$[\mu \mathrm{m}]$ & ['] & {$\left[{ }^{\circ}\right]$} & {$\left[\mathrm{m} \cdot \mathrm{s}^{-1}\right]$} & {$\left[\mathrm{m} \cdot \mathrm{s}^{-1}\right]$} & {$\left[\mathrm{m} \cdot \mathrm{s}^{-1}\right]$} & {$\left[\mathrm{m} \cdot \mathrm{s}^{-1}\right]$} & [N] \\
\hline 20 & 60,7 & 135,9 & 41,2 & 6,6 & 73,4 & $-6,4$ & $-40,2$ \\
\hline 50 & 58,1 & 136,0 & 45,9 & 6,6 & 73,8 & $-6,3$ & $-47,6$ \\
\hline 100 & 53,8 & 136,1 & 54,0 & 6,6 & 73,8 & $-6,3$ & $-60,0$ \\
\hline 150 & 49,1 & 136,0 & 64,2 & 6,6 & 74,2 & $-6,3$ & $-74,2$ \\
\hline 200 & 43,3 & 136,1 & 78,7 & 6,6 & 74,1 & $-6,3$ & $-91,3$ \\
\hline
\end{tabular}

Table 4 and 5 list simulated flow angles and flow velocities of the spool CE with chamfer widths ranging from 20 to $200 \mu \mathrm{m}$ for the spool position of $0.6 \mathrm{~mm}$, the pressure drop of 50 bar for the inlet throttling and the outlet throttling. Again, the spool strokes were also lowered by the magnitude of the radius so the inlet area remained constant.

Table 4: Flow angles and flow velocities simulated for different chamfer widths in case of the inlet throttling

\begin{tabular}{|c|c|c|c|c|c|c|c|}
\hline B & $\varepsilon_{1}$ & $\varepsilon_{2}$ & $\mathbf{v}_{1, \mathrm{x}}$ & $v_{2, x}$ & $v_{1, r}$ & $v_{2, r}$ & $F_{\mathrm{Fl}}$ \\
\hline$[\mu \mathrm{m}]$ & {$\left[{ }^{\circ}\right]$} & {$\left[{ }^{\circ}\right]$} & {$\left[\mathrm{m} . \mathrm{s}^{-1}\right]$} & {$\left[\mathrm{m} \cdot \mathrm{s}^{-1}\right]$} & {$\left[\mathrm{m} . \mathrm{s}^{-1}\right]$} & {$\left[\mathrm{m} \cdot \mathrm{s}^{-1}\right]$} & {$[\mathrm{N}]$} \\
\hline 20 & 56,7 & 140,5 & 48,8 & 7,1 & $-74,3$ & 5,8 & $-49,9$ \\
\hline 50 & 57,1 & 139,7 & 47,7 & 7,2 & $-73,9$ & 6,1 & $-48,3$ \\
\hline 100 & 57,4 & 140,4 & 47,1 & 7,1 & $-73,5$ & 5,9 & $-47,2$ \\
\hline 150 & 56,7 & 137,6 & 48,3 & 6,6 & $-73,5$ & 6,1 & $-48,0$ \\
\hline 200 & 55,5 & 136,3 & 50,8 & 6,3 & $-73,9$ & 6,0 & $-50,5$ \\
\hline
\end{tabular}

Table 5: Flow angles and flow velocities simulated for different chamfer widths in case of the outlet throttling

\begin{tabular}{|c|c|c|c|c|c|c|c|}
\hline B & $\varepsilon_{1}^{\prime}$ & $\varepsilon_{2}^{\prime}$ & $v_{1, x^{\prime}}$ & $v_{2, x^{\prime}}$ & $v_{1, r^{\prime}}$ & $v_{2, r^{\prime}}$ & $F_{F I^{\prime}}$ \\
\hline$[\mu \mathrm{m}]$ & {$\left[{ }^{\circ}\right]$} & {$\left[{ }^{\circ}\right]$} & {$\left[\mathrm{m} . \mathrm{s}^{-1}\right]$} & {$\left[\mathrm{m} . \mathrm{s}^{-1}\right]$} & {$\left[\mathrm{m} . \mathrm{s}^{-1}\right]$} & {$\left[\mathrm{m} \cdot \mathrm{s}^{-1}\right]$} & {$[\mathrm{N}]$} \\
\hline 20 & 62,2 & 136,0 & 38,7 & 6,6 & 73,4 & $-6,4$ & $-38,2$ \\
\hline 50 & 59,5 & 136,1 & 43,3 & 6,6 & 73,5 & $-6,3$ & $-45,3$ \\
\hline 100 & 54,6 & 136,2 & 52,3 & 6,6 & 73,6 & $-6,3$ & $-58,4$ \\
\hline 150 & 46,1 & 136,1 & 69,9 & 6,6 & 72,5 & $-6,3$ & $-78,8$ \\
\hline 200 & 42,2 & 136,0 & 78,8 & 6,6 & 71,5 & $-6,3$ & $-89,6$ \\
\hline
\end{tabular}

\section{Discussion}

Figure 10 and 11 reveal that the average radial flow velocities depend slightly on the flow direction. The flow direction influences the discharge coefficient. Since the approximated radial flow velocities are calculated according to eq. 5 , respectively eq. 6 with quantities determined from the measurements, they perfectly match the measured values. The discharge coefficient depends on many factors such as metering-edge shape, flow direction, oil temperature etc. So this coefficient should be individually determined to achieve more accurate values when approximating the radial flow velocities for different metering-edge shapes. It can be seen that larger spool positions lead to lower radial flow velocities. This results from the fact that the discharge coefficient decreases when the spool position increases. 
Figure 12 shows that the smallest radial velocities are obtained with the spool BE. This fits to theoretical modelling since the bevel confines the flow behind the metering area. In fact, the smallest metering area of the spool BE is cone-shaped as it is created as a perpendicular distance from the bevel to the sleeve edge. However, the smallest metering area was not considered in this study to allow the comparison of the flow angles for the same metering areas.

It can be concluded from tab. 1 that the simulated radial flow velocities match the measured ones. The approximate relative error of the inlet radial flow velocities is -4.5 percent, respectively a little less for the outlet radial flow velocities. This confirms that the evaluation method of simulated flow velocities is suitable.

The inlet-throttling velocity vectors on the chamber inlet are visualised in fig. 14 for the spool SE for a spool position of $0.6 \mathrm{~mm}$ and a pressure differential of 50 bar. It is evident that the maximum velocity is located closer to the sleeve edge. This can also be seen in fig. 18. It was also observed that the velocity distribution is almost independent of the angular position. On the contrary, the velocity distribution on the chamber outlet is not uniform regarding the angular position. Figure 15 shows that the flow angle strongly varies with the x-position. Moreover, fig. 16 confirms that the flow circulates in the groove between two outflow conduits. The profiles of radial flow velocities are qualitatively similar for different pressure differentials, as illustrated in fig. 17, 18 and 19.

Figure 20 reveals that the flow angles $\varepsilon_{1}{ }^{\prime}$ are greater than flow angles $\varepsilon_{1}$ when comparing both flow directions. The curves of the flow angles $\varepsilon_{1}$ and $\varepsilon_{1}{ }^{\prime}$ are qualitatively similar. On the other hand, it is apparent from fig. 21 that the flow angles $\varepsilon_{2}{ }^{\prime}$ are almost constant over the flow rate, while the flow angles $\varepsilon_{2}$ are functions of the flow rate.

Two findings are visible in fig. 22. On the one hand, the flow angles $\varepsilon_{1}{ }^{\prime}$ of the bevel-edged spool (BE) are the lowest compared to other spools. It approximately equals $33^{\circ}$, although the bevel angle is $45^{\circ}$. Thus the fluid does not flow along the bevel in case of the outlet throttling. On the other hand, a similar effect is caused by the $0.3 \times 60^{\circ}$-chamferedged spool (CE) resulting in flow angle $\varepsilon_{1}{ }^{\prime}$ values of approximately $45^{\circ}$. Figure 23 shows that the flow angles $\varepsilon_{2}{ }^{\prime}$ of the spool SE13 deviate from the flow angles of other spools. Besides the spool SE13, the flow angles of other spools are almost equal and constant.

Table 2 shows that the average flow angles on the inlet area differ from von Mises' value of $69^{\circ}$, and the average outlet flow angles are much larger than the usually assumed value of $90^{\circ}$. Moreover, the fillet radius influences the flow angles and axial flow velocities significantly. Hence, the flow forces also vary. The radial flow velocities remain approximately constant.

It is apparent from tab. 3 that the flow direction influences the average flow angles and axial flow velocities. Compared to the values for the inlet throttling, the inlet flow angles and flow velocities for the outlet throttling vary more, which results in a larger variation of the flow force. Particularly, the maximum flow-force of the outlet throttling is $-91.3 \mathrm{~N}$ compared to $-56.0 \mathrm{~N}$ of the maximum inlet throttling.

It can be seen in tab. 4 and 5 that the variation of the chamfer width impacts the flow quantities. In case of the inlet throttling, this impact is much lower compared to the outlet throttling. The flow angles $\varepsilon_{l}$ are almost constant in all simulated cases, while the flow angles $\varepsilon_{l}$ ' vary from $42.2^{\circ}$ to $62.2^{\circ}$. Consequently, the flow forces vary much as well.

\section{Conclusions}

Within this paper, flow angles and flow velocities of a $2 / 2$ way spool-type test valve were investigated from measurements and CFD-simulations. Spools with differently shaped metering edges were analysed in both flow directions.

The results show that the radial flow velocities can be accurately approximated if the discharge coefficients are known. The flow direction impacts the flow angles and hence the flow velocities. In addition, the shape of the metering edge influences the flow angles and the flow velocities. An increasing chamfer width, respectively an increasing fillet radius, both result in lower flow angles. The profiles of radial flow velocities on the chamber outlet prove that the velocity-vector distribution is not uniform regarding the angular position for the inlet throttling.

All in all, among others the flow angles and the radial flow velocities are needed to calculate the flow force. The latter can be approximated accurately when the discharge coefficient is known. The flow angles are difficult to estimate analytically since there is no analytical model describing the relations between the flow angles and different parameters. However, nowadays, the flow force can be evaluated relatively quickly using CFD simulations.

\section{References}

[1] Von Mises, R.: Berechnung von Ausfluss- und Überfallzahlen. In: Zeitschrift des Vereins Deutscher Ingenieure, 1917.

[2] Backé, W., Tatar, H.: Untersuchung des Einflusses von Störkräften auf den Schaltvogang bei Wegeventilen der Hydraulik. Forschungsberichte des Landes NordrheinWestfalen, Opladen: Westdeutscher Verlag, 1975.

[3] Murrenhoff, H.: Grundlagen der Fluidtechnik. Teil 1: Hydraulik. Umdruck zur Vorlesung. 8. Aufl. Herzogenrath: Shaker (Reihe Fluidtechnik U3), 2016.

[4] Ye, Yi et al.: Effects of groove shape of notch on the flow characteristics of spool valve. In: Energy Conversion and Management 86, p. 1091-1101, 2014.

[5] Schrank, K., and Murrenhoff, H.: Beschreibung der Strömungskraft in Längsschieberventilen mittels Impulserhaltung. In: O+P Fluidtechnik 4, 2013. 
[6] Tanaka, K. et al.: Steady and Unsteady Flow Force acting on a Spool Valve. In: Fluid Power and Motion Control, 2012.

[7] Lugowski, J.: Steady-State Flow Force Compensation in a Hydraulic Valve. Purdue University, 2013.

[8] Yuan, Q., Li, P.Y.: Using Steady Flow Force for Unstable Valve Design: Modeling and Experiments. In: J. Dyn. Sys., Meas., Control, 127(3), p. 451, 2005.

[9] Okungbowa, N., et al.: Determining the Steady State Flow Forces in a Rim Spool Valve using CFD Analysis. In: PTMC, 2005.

[10]Kipping, M.: Experimentelle Untersuchungen und numerische Berechnungen zur Innenströmung in Schieberventilen der Ölhydraulik. Technische Hochschule Darmstadt, Dissertation, 1997.

[11] Bordovsky, P., Murrenhoff, H.: Investigation of SteadyState Flow Forces in Spool Valves of Different Geometries and at Different Oil Temperatures With the Help of Measurements and CFD Simulations. In: Proceedings of BATH/ASME 2016 Symposium on Fluid Power and Motion Control, 2016.

[12]Del Vescovo, G.; Lippolis, A.: Three-Dimensional Analysis of Flow Forces on Directional Control Valves. In: International Journal of Fluid Power 4 (2), 2003

[13]Borghi, M. et al.: Influence of Notch Shape and Number of Notches on the Metering Characteristics of Hydraulic Spool Valves. In: International Journal of Fluid Power, 6(2), pp. 5-18, 2005.

[14] Merritt, H.E.: Hydraulic Control Systems. New York: John Wiley \& Sons Inc, 1967.

\section{Nomenclature}

\begin{tabular}{|c|c|c|}
\hline Designation & Denotation & Unit \\
\hline$\alpha_{D}$ & Discharge coefficient & - \\
\hline$\varepsilon$ & Jet angle at vena contracta & $\circ$ \\
\hline$\varepsilon_{1 / 2}$ & $\begin{array}{l}\text { Inlet/Outlet flow angle for the } \\
\text { inlet throttling }\end{array}$ & $\circ$ \\
\hline$\varepsilon_{1 / 2}$ & $\begin{array}{l}\text { Outlet/Inlet flow angle for the } \\
\text { outlet throttling }\end{array}$ & $\circ$ \\
\hline$\rho$ & Fluid density & $\mathrm{kg} / \mathrm{m}^{3}$ \\
\hline$A$ & Area & $\mathrm{m}^{2}$ \\
\hline$A_{1 / 2}$ & $\begin{array}{l}\text { Inlet/Outlet area for the inlet } \\
\text { throttling }\end{array}$ & $\mathrm{m}^{2}$ \\
\hline$A_{1 / 2}$ & $\begin{array}{l}\text { Outlet/Inlet area for the outlet } \\
\text { throttling }\end{array}$ & $\mathrm{m}^{2}$ \\
\hline$B$ & Chamfer width & $\mathrm{m}$ \\
\hline
\end{tabular}

\begin{tabular}{|c|c|c|}
\hline$F_{F l}$ & $\begin{array}{l}\text { Steady-state flow force for the } \\
\text { inlet throttling }\end{array}$ & $\mathrm{N}$ \\
\hline$F_{F l}$ & $\begin{array}{l}\text { Steady-state flow force for the } \\
\text { outlet throttling }\end{array}$ & $\mathrm{N}$ \\
\hline$F_{x}$ & Net axial force & $\mathrm{N}$ \\
\hline$I$ & Momentum & kg.m/s \\
\hline$L$ & Length of the spool chamber & $\mathrm{m}$ \\
\hline$p$ & Pressure & $\mathrm{Pa}$ \\
\hline$p_{1}$ & Pressure on the valve inlet & $\mathrm{Pa}$ \\
\hline$p_{2}$ & Pressure on the valve outlet & $\mathrm{Pa}$ \\
\hline$Q$ & Flow rate & $\mathrm{m}^{3} / \mathrm{s}$ \\
\hline$R$ & Fillet radius & $\mathrm{m}$ \\
\hline$v_{1 / 2}$ & $\begin{array}{l}\text { Inlet/outlet flow velocity for the } \\
\text { inlet throttling }\end{array}$ & $\mathrm{m} / \mathrm{s}$ \\
\hline$v_{1 / 2, r / x}$ & $\begin{array}{l}\text { Average inlet/outlet radial/axial } \\
\text { flow velocity for the inlet } \\
\text { throttling } *\end{array}$ & $\mathrm{~m} / \mathrm{s}$ \\
\hline$v_{1 / 2}$ & $\begin{array}{l}\text { Outlet/inlet flow velocity for the } \\
\text { outlet throttling }\end{array}$ & $\mathrm{m} / \mathrm{s}$ \\
\hline$v_{1 / 2, r / x}$ & $\begin{array}{l}\text { Average outlet/inlet radial/axial } \\
\text { flow velocity for the outlet } \\
\text { throttling * }\end{array}$ & $\mathrm{m} / \mathrm{s}$ \\
\hline$x$ & Relative $\mathrm{x}$-coordinate & $\mathrm{m}$ \\
\hline$x_{1}$ & Spool position & $\mathrm{m}$ \\
\hline$x_{2}$ & $\begin{array}{l}\text { Width of the outlet } \\
\text { circumferential groove }\end{array}$ & $\mathrm{m}$ \\
\hline$\Delta p$ & Pressure differential & $\mathrm{Pa}$ \\
\hline$\Delta r$ & Height of the radial clearance & $\mathrm{m}$ \\
\hline
\end{tabular}

\section{Acknowledgments}

The IGF research project $18569 \mathrm{~N} / 1$ of the research association Forschungskuratorium Maschinenbau e. V. FKM, Lyoner Straße 18, 60528 Frankfurt am Main was supported from the budget of the Federal Ministry of Economic Affairs through the AiF within the scope of a program to support industrial community research and development (IGF) based on a decision of the German Bundestag. 